\section{Openness and the MRC}

SIR-Some of the ambiguities of the Medical Research Council (MRC)'s peer review system have been addressed by its secretary, Dr D. A. Rees (Nature 347, $116 ; 1990)$, but he made no comment on its finances. In 1989, the current parliamentary grant-in-aid to the MRC was increased by as much as 53 per cent, to be spread over the next three years. Satisfaction at this generous increase was expressed by the council. However, the secretary has now stated, in a letter to staff purporting to explain unit closures, that the MRC has not received the necessary protection against inflation, nor enough provision for current pay awards.

One of the recent actions to overcome the current 'deficit' is to close two of its internationally renowned units in Cambridge. One of these, the Molecular Neurobiology Unit, set up only in 1985 , last year also underwent the detailed scrutiny of the peer review process. After this lengthy and expensive procedure, five of its six groups were alpha-rated, the referees consulted found the work of "the highest international standard" and the review subcommittee found the unit to be "good value for money" and warmly recommended that the work should continue. Subsequently, the MRC Neurosciences Board ("the wider scientific perspective" noted by Rees in his letter to Nature) also congratulated the unit on its achievements and recommended continuation of the work in some form, even after the present director's retirement in late 1992, setting up a search committee for a successor. Amazingly, however, the council itself subsequently rejected all these positive recommendations (from the many distinguished scientists in a wide spectrum of fields serving on the board, the review subcommittee and the panel of seven referees) and voted to close down the unit in 1992. One can only speculate on what advice they received and from whence it came

In its wisdom, the MRC's new "strategy committee" immediately decided that this unit was now a prime target for making up a deficit, unheard of until then, and have required that one-third of the total budget for salaries and expenses be axed, a process to be started immediately. One has to ask, first, why there is a current deficit, when the MRC has received an extra $£ 82$ million over three years, plus additional funds towards the pay settlement. If there is not poor financial management, a proper explanation should surely be forthcoming. When large sums of public money are invested in new ventures (as occurred here in 1985), the scientific community at least is entitled to know why work, rated highly after intensive review, is to be cut off in midstream, without warning. Is this the way to run a business? To claim vaguely an intention to spend more on molecular neurobiology in the unspecified future (or to start up other new ventures) is hardly a convincing reason for disabling current research in this field, still underrepresented in the United Kingdom.

While members of this unit have recently been warned not to make improper criticism of council's policy or decisions, nor any that may draw the secretary into the public arena, we have to concur, Sir, with your own opinion (Nature 346, 684; 1990) that more openness is essential if public confidence in the MRC is to be maintained.

P. J. BARNARD

MRC Molecular Neurobiology Unit, University of Cambridge Medical School, Hills Road,

Cambridge CB2 2QH, UK

\section{Imperial echoes}

SIR - If using imperial measures were as dreadful as Ernest L. Asten (Nature 346, $506 ; 1990$ ) asserts, there would be two inevitable consequences. First, countries that persist with this ridiculous system would languish among the also-rans of the international community. Second, citizens of those countries would clamour to go metric and seize any opportunity to do so with enthusiasm. In fact, neither prediction is borne out by experience.

Asten must be considerably perplexed that his native land which, according to his letter, hardly knows how to build a house properly, has been the economic, technological and military giant of the twentieth century. Using British measures, it put the first men on the Moon, constructed the tallest buildings on Earth and established the world's highest standard of living. Having resided in Belgium, a metric country, the United States, a non-metric country, and Great Britain, which is somewhere in between, I can reassure Asten that houses are no better built here or in Belgium than in his own country while the plumbing is a great deal better his side of the pond.

Blackheath Grove, London SE3 ODH, UK

\section{HIV and AIDS}

SiR-Peter Duesberg (Nature 346, 788; 1990) requested data on matched groups of homosexual men or haemophiliacs which could show that only subjects infected with human immunodeficiency virus (HIV) developed AIDS. Such data have been available for some years in several cohort studies, and are among the many reasons why clinical scientists have been puzzled by Duesberg's stance. For example, we show below the natural history of two cohorts from our experience. Three hundred and fourteen initially asymptomatic sexually active homosexual men have been studied longitudinally since their recruitment between 1982 and 1984. They were tested for HIV antibody when testing became available in 1984 , and the cohort was found to contain 144 seronegatives and 170 seropositives; information of sexual behaviour and recreational drug use had been carefully obtained at recruitment and follow-up visits, and the two groups were closely matched. Since 1984, 25 initially seronegative subjects have seroconverted: by June 1990, AIDS had developed in 62 seropositive men, and in 6 seroconverters, after seroconversion. None of the seronegative group have developed AIDS. There have been 48 deaths from all causes (see table) in the HIV-positive subjects, and none in the seronegatives.

Similarly, 41 severe haemophilia A subjects have been followed longitudinally since 1979. Testing in 1984 revealed 26 seropositive and 15 consistently HIV seronegative. Nine out of 26 seropositive subjects have now developed AIDS, but none of the seronegatives. Mortality in the two groups from all causes is 7 out of 26 for the HIV-positive, but none in the HIVnegative group. These data clearly support a pathogenic role for HIV infection.

\begin{tabular}{lll}
\hline Outcome & HIV & HIV \\
& positive & negative \\
Homosexual men & 194 & 120 \\
AIDS & $68(35 \%)$ & 0 \\
Deaths* & $48(25 \%)$ & 0 \\
Haemophiliacs & 26 & 15 \\
AIDS & $10(38 \%)$ & 0 \\
Deaths* & $7(27 \%)$ & 0 \\
\hline
\end{tabular}

* Death from all causes except suicide or accident.

ANTHONY J. PINCHING DONALD J. JEFFRIES

J.R. WILLIAM HARRIS

St Mary's Hospital and Medical School, London W2 1PG, UK

DAVID SWIRSKY

JONATHAN N. WEBER

Royal Postgraduate Medical School,

Hammersmith Hospital,

London W12 ONN, UK

\section{Help wanted}

SIR-I am preparing to write the first complete biography of Joseph Priestley. It will examine his religious and political life as well as his scientific endeavours. If any of your readers have or know of diaries, journals or letters by or referring to Priestley, I should be grateful if they would write to me at the address below.

The Flat, 16 Highbury Place,

RICHARD B. FISHER

London N5 1QP, UK 